\title{
Metatheorizing Structural Human Ecology at the Dawn of the Third Millennium
}

\author{
Thomas J. Burns' \\ Department of Sociology, \\ University of Oklahoma, Norman, United States \\ Thomas K. Rudel \\ Department of Sociology, \\ Rutgers University, New Brunswick, United States
}

\section{Abstract}

While its processes have been unfolding for centuries, some aspects of human interaction with the natural environment are unprecedented. In recent centuries, the world has experienced unparalleled technological change, wealth accumulation and population growth and concentration; these have led to extraordinary levels of other problems, particularly environmental degradation. Focusing on mismatches between the adaptive cycle and the organization of the world economy, we examine material and cultural changes that lead to social and ecological devastation. We apply our theoretical framework to one of the largest ecological and social catastrophes since the Industrial Revolution- the Irish Potato Famine of the 1840s. There are a number of lessons, particularly in terms of the relations of production and humankind's connection with the natural environment. It is now as important as ever to learn from past mistakes and modify current modes of theory and analysis as history moves into the Third Millennium.

Keywords: Potato Famine, adaptive cycle, coupled natural and human systems

\footnotetext{
1 Author contact: Thomas J. Burns, Dept of Sociology, University of Oklahoma, 331 Kaufman Hall, Norman, OK 73019. Email: tburns@ou.edu. An earlier version of this paper was presented at the 2014 conference of the Society for Human Ecology, Bar Harbor, Maine.
} 


\section{Introduction}

The advent of coupled natural and human ( $\mathrm{CNH})$ systems research (in our opinion, human ecology by another name) has in recent years fostered welcome increases in empirical research, but comparable kinds of theoretical syntheses have been slow to appear. Metatheoretical advances in human ecology could be achieved in several different ways, both of which we explore in this paper. One path to metatheory would merge models with different parent disciplines, in particular, the adaptive cycle from ecology and the world system from sociology. A second path would focus on the theoretical architecture of this combined approach, the appropriate set of variables, its scalar properties, and the measures that would capture the dynamics of change. These paths are not mutually exclusive. Here we take some initial steps down each one of them. Pursued in tandem, these analytic directions could provide us with a theory that could serve as a focal point for the new wave of work in human ecology prompted by the environmental crisis.

\section{Merging the adaptive cycle and the world economy}

We begin with brief sketches of the adaptive cycle and the world economy. Before we outline the differences between the two models, it might be useful to underline one of their shared attributes. Both of them represent "populationist approaches" to $\mathrm{CNH}$ theories in that they outline mechanisms of change that characterize how communities cope with the larger contingencies that they face (McLaughlin, 2012). ${ }^{2}$ The dynamics of these mechanisms differ dramatically, but a glance at the most common graphical depictions of the two systems suggests how the two theories might be combined. The metaphor that captures the adaptive cycle most clearly is a temporal one, with communities progressing through stages. The metaphor that summarizes the world system most clearly is a spatial one: a map, in which systems have cores, semi-peripheries, and peripheries (e.g., Wallerstein, 2004; Chase-Dunn \& Hall, 1997).

\footnotetext{
2 We acknowledge here the long-standing debates and discussions about the respective merits and pitfalls of individual- and population-level analyses. We do not engage those debates here, and point the interested reader to Richerson (1977), Fain, Burns, and Sartor (1994), Dietz and Burns (1992), Vayda (1988), Becker (1976), and Richerson and Boyd (1998) for elaboration and discussion. While we recognize the utility of microlevel approaches, we nonetheless utilize for this paper, a macro-level framework that we believe is more in concert with a structural view of human ecology.
} 
Systems ecologists, perhaps most notably C. S. (Buzz) Hollings (Hollings, 1973; Gunderson \& Hollings, 2002), developed a model of a recurrent sequence of changes, dubbed "the adaptive cycle," that they describe as characterizing most communities of living things. They chose to subtitle the book that presents a summary of the adaptive cycle, "Understanding transformations in human and natural systems." In truth, almost all of the published applications of the adaptive cycle model (e.g., Walker \& Salt, 2006) focus on ecological communities. They do not represent a test of the model's applicability to human communities, and have little to say about changes in those human communities. ${ }^{3}$

Still the model has impressive analytic reach and could be used as an important component in understanding human ecology. The structure of the system changes dramatically as it moves through the adaptive cycle. Four stages characterize these processes of change: a system that expands, then collapses, then reorganizes itself, and then proceeds to begin expanding again. In a further and helpful simplification of the model, Ruth DeFries (2014) describes three essential stages in the adaptive cycle: a ratcheting up (when it expands) of the system, a hatcheting (when things fall apart) of the system, and finally, a pivoting, often accompanied by new technologies, when the systems begins to reassemble and grow in size again. Structural changes in communities accompany these changes in process. For example, as systems expand, they become more tightly coupled, more culturally complex, and less resilient in the aftermath of external shocks. The most recent work on adaptive cycles has expanded the scope of these adaptive dynamics to the entire globe. The concept of telecoupling describes how processes of change in distant, seemingly disconnected places represent, in fact, different manifestations of a single, larger global dynamic of climate change (Liu et al., 2014).

Considering how to apply the adaptive cycle model to coupled natural and human communities exposes some lacunae in the model. In particular, it contains few ways of meaningfully representing the political power that structures so much of human affairs. Politico-economic conflict does occur in the model, largely as contests between communities at different scales. For example, fast-moving, local entities (including local governments) may revolt against conservative strictures imposed by slow-moving institutions, such as central governments, embedded economic systems, and/or foreign hegemonic powers, invested in the maintenance of growth in the overall system. Similarly, when disaster strikes a local community, the hegemonic power structure typically works to restore the local unit to its former state (Gunderson \& Holling, 2002). Groups exercise power

3 The journal Ecology and Society is edited by scholars who endorse the adaptive cycle and employ a resilience framework in which adaptive cycle models would fit, but few of the articles in the journal test the adaptive cycle model in a meaningful sense. 
over one another in these extraordinary circumstances. More routine exertions of power that, for an example, try to maintain elite privileges or a trajectory of growth in a community seem difficult to incorporate into adaptive cycle models.

The world systems models would seem to be strong where adaptive cycle models are weak. The people inhabiting the different spaces in the world system have different amounts of power, with people in the core able to exert power over people in the periphery. Power ebbs and flows as the core of the world system shifts from country to country across historical periods, but the system retains its core-periphery organization (Chase-Dunn \& Hall, 1997). The world system has a cyclical dimension, referred to as Kondratiev cycles (Barnett, 1998), in which the whole system undergoes perturbations every several generations, oftentimes associated with the introduction of new technologies. While these cycles are not necessarily as marked or as central to the operation of the world system model as are the stages in the adaptive cycle model, they nonetheless represent another way in which economic and ecological systems are related, even if not tightly coupled.

Ecologists in the Marxist tradition have worked to develop a conceptual apparatus for integrating ecological variables into broader global systems. James O'Connor, for example, has argued that the second contradiction of capitalism implies that capitalism will eventually destroy the ecological bases for the wealth that it produces for the capitalist class (O'Connor, 1998; also see Spence, 2000). The idea of unequal exchange between core communities and peripheral populations shows how, over time, trade between wealthy and poor nations fails to incorporate into the prices of goods the costs of the ecological degradation entailed in the production of these goods in the periphery (Jorgenson, 2006; Burns, Kick, \& Davis, 2006). The Netherlands fallacy explains how these patterns of vertical trade relieve human pressures on natural resources in the core countries at the cost of increasing these pressures in peripheral countries (Meyfroit, Rudel, \& Lambin, 2010).

The difficulty with these analyses is that they do not go far enough in their exploration of ecological variables. For example, one could make the case that unequal exchange routinely results in the creation of ecosystems on the Global South that are dominated by invasive species such as the bracken fern in the Southern Yucatan (Schneider \& Fernando, 2010). Once established, these places are difficult to transform into productive landscapes, either ecologically or economically. As Meyfroit, Rudel, \& Lambin (2010) point out, the exploitation and exhaustion of increasingly fine-grained swathes and more accessible rain forests in smaller countries often aggregate to devastating macro-level effects. These practices tend to drive timber and agricultural enterprises to focus their 
land-clearing efforts on the few countries with large blocks of still unexploited forests, such that there truly are now precious few places left where there are truly virgin forests.

World systems and structural human ecological analyses could help to inform the other. What one would want to see is a set of analyses in which the adaptive cycle and the world system interpenetrate, and, in so doing, produce robust explanations for change in socioecological systems. How do we do this? Perhaps, an example here will help.

\section{A brief example of the merged approach: The Irish Potato Famine}

By a lonely prison wall, I heard a young girl calling: Michael, they have taken you away; for you stole Trevelyan's corn, so the young might see the morn. Now the prison ship lies waiting in the bay ... Against the famine and the Crown, [he] stood up, they brought [him] down ... Now she'll live and hope and pray, for her love in Botany Bay, but it's lonely here, in the fields of Athenry ... (From the Irish folk song, The Fields of Athenry, by Pete St. John).

The Irish Potato Famine of the late 1840s represents a singular event in the 19thcentury demographic history of Europe. More than a million Irish probably perished of hunger-related causes during the 1840s and an additional million emigrated from Ireland to other parts of the world - primarily, but by no means solely, to the Americas - in successive waves beginning in the 1840s.

Elements of the adaptive cycle explain both the demise and eventual recovery of Irish agro-ecology during the mid-19th century. Described as "the most lethal natural disaster in 19th century Europe" (O'Grada, 1999), the famine, like other disasters (McLaughlin \& Dietz, 2008), had historical roots. It stemmed from the introduction and spread of potatoes in Europe after 1600. In Ireland, the abundance of the potato harvests stimulated a considerable increase in rural populations during the first few decades of the 19th century. A corresponding increase in the amount of land being cultivated for potatoes also occurred. The genetic uniformity of the harvested potatoes also grew during this period as smallholders, as well as absentee landowners, adopted the highestyielding variety of potato. This last development made Irish smallholders and tenant farmers more vulnerable to crop failures. In the 1840s a fungus began to decimate the crops, leading to widespread starvation, particularly among the smallholders. When the crops failed, landlords evicted tenants who could no longer pay their rents because they no longer had potatoes to sell. Tenants evicted lodgers (farm workers) because they no longer needed the additional labor to harvest the decimated crops. Evicted tenants and lodgers appealed to 
British-run workhouses in the cities, but the colonial government provided little in the way of relief ( $\mathrm{O}^{\prime}$ Grada, 1999). Impoverished and weakened from malnutrition, the Irish died either from starvation or from opportunistic diseases (Mokyr \& O'Grada, 2002).

Gradually, in the 1850s new fungus-resistant strains of the potato, bred in the Americas, were introduced, and large numbers of the younger Irish emigrated, so the smallholders' vulnerability declined (DeFries, 2014). The sequence here resembles the adaptive cycle. The system ratchets up in the early 19th century, disintegrates (the hatchet) during the 1840s, and pivots after the 1850s with the introduction of the new varieties of potato and the emergence of more agro-biodiverse set of cultivars.

This account of the Irish Potato Famine provides only a partial explanation for all of the deaths by famine. Famines in a world with extensive, long-distance trade only occur because elites make political choices to deprive marginal groups of food supplies (Sen, 1983). In the case of Ireland, at the same time that Irish smallholders and tenant farmers were increasing their reliance on the potato and their vulnerability to crop failures, vertical trade with overseas English consumers increased. English landlords with extensive landholdings in Ireland increased their cultivation of wheat and corn for export to consumers in English cities. When the potato crops began to fail, the English landlords refused to divert the supplies of Irish wheat and corn to feed the Irish people unless they could pay for the foodstuffs, which, with no crops to sell, they could not. The landlords exported the wheat and livestock to England and starvation ensued among the Irish.

Differential amounts of political power, explicable in terms of the world system, shed light on this dynamic. Given their dominant political position, the English owned prime agricultural lands in Ireland. The English landowners' allegiance to the country's core consumers and their political representatives most likely stemmed from the advantaged politico-economic position of these people. These factors would explain the landlords' unwillingness to reserve their harvests to feed the tenants on their lands.

This material advantage then filters its way into an ideological apparatus that serves to legitimate this unequal exchange. What is seen as "truth" becomes, in this sense, a function of the social definition expressed through the rhetoric of those in power (Burns \& LeMoyne, 2003b). With power comes agency, and the powerful can assert that agency on multiple levels - not only on the structural, but on the cultural level as well, particularly by the shaping of discourse (Dietz \& Burns, 1992; Burns, 1999). In our example of the Irish Potato Famine, the major British colonial administrator at the time was Charles Edward Trevelyan. Even as shiploads of the substitute crops of corn and wheat were 
expropriated through the 1840s from Ireland so that absentee landlords could continue to profit, Trevelyan publicly proclaimed the famine as "God's way of removing surplus population." He refused help to those in need (whose need he had had no small hand in extending, if not causing!), with the rationale that any aid would encourage laziness and shiftlessness among the Irish.

In sum, the crop failures leading to the famine appear largely explicable in terms of an adaptive cycle, but the absence of any effort to come to the assistance of the starving Irish tenant farmers become most explicable in terms of a world system in which British hegemonic interests reigned supreme. The most complete account of the famine could therefore draw upon both adaptive cycle and world system theory; and a metatheory with adaptive cycle and world system components would seem, at least in this instance, to have considerable heuristic value.

\section{A brief excursus on metatheory}

One of the seminal figures in developing the ideas underpinning metatheory in the social sciences, George Ritzer, has identified three major uses of metatheory: to better understand the work itself $(\mathrm{Mu})$; the identification of overarching themes in the literature (Mo); using theory as a prelude to further theorizing and empirical work (Mp) (Ritzer, 1975, 1991, 1992). We see our work as contributing on all three fronts, but particularly in terms of the third usage.

Particularly, given the daunting social and environmental problems faced by researchers moving into the Third Millennium, it is important to have a sense of how a given piece of research helps inform the whole. Major theoretical ideas that run throughout the research and inform it will serve a tremendous heuristic value. In the words of psychologist Kurt Lewin, "There is nothing more practical than a good theory."

There is a growing body of literature in structural human ecology, and we believe the field will benefit greatly from efforts to identify major trends and overarching themes of the work in the area. Recent work in a collection of essays by Dietz and Jorgenson (2013) takes steps in that direction (in particular, see Dietz \& Jorgenson, 2013; York, 2013; Dietz, 2013; Jorgenson, 2013). We see our work in that spirit.

What we offer in this paper is what we envision as a useful metatheoretical framework for structural human ecology and related fields. We do believe that it can inform research now and in the short-run future, and we hope and trust that, in the long run, something more robust and universal will supplant it. In the meantime, we offer it as a heuristic device. 


\section{Structural mismatches as metatheoretical throughlines}

We can see several metatheoretical lessons in the tragic history of sociostructural precursors and consequences of the Irish Potato Famine. First, there are serious mismatches between the way natural ecologies actually operate, and the way the institutions of modernity operate. We could unpack any number of these institutions, but for the purposes of this article-length work, we will focus on one of the most stark sets of mismatches - that between the human ecological adaptive cycle on the one hand, and the way the global economy is organized on the other.

\section{The entropy of ideas in general, and of neo-classical economic ideas in particular}

A number of interrelated assumptions underlie the logic of global trade networks. These are at cross purposes with, and often antithetical to, ways in which ecological cycles actually operate. We look in particular at the ideas that underpin the world economy. Many of them go back to Adam Smith (1776), and remain, in one form or another, even today.

Yet as ideas develop and are refined through intellectual effort and research, their popular understanding may degrade. Entropy is an important metaphor for what happens in the diffusion of ideas (Burns \& LeMoyne, 2003a). Here, we re-examine how ideas from a crude, dumbed-down version of 18th-century economics has come to dominate much of the economic and social practices since then. A number of the ideas have been remarkably immune to significant change, and are as prevalent now, in mainstream thinking here in the 21 st century (see Lux, 1990; Stiglitz, 2003), as they were in the 19th-century Potato Famine. ${ }^{4}$

A number of ideas from economics make sense on some level yet, when taken to extremes, become toxic (Weaver, 1984; McCloskey, 1998). Some of these most notably include the emphasis on economies of scale; hyperspecialization; the law of comparative advantage; the reification of the "invisible hand" of the market; the tendency to externalize latent aspects of the production process; and the assumption of a world populated with rational actors with access to large amounts of undistorted information that they understand and act upon deliberately. Also of particular importance in terms of the natural ecology is "discounting the future." Let us examine these one by one.

\footnotetext{
4 Many of the structural inequalities and power dynamics that we examine here in the case of Irish Potato Famine have been found in the relations of production of other globally traded commodities, including cotton (Beckert, 2014), sugar (Mintz, 1985), and coffee (Jacob, 2015).
} 


\section{Mismatches of scale}

The principle of economies of scale holds that with increasingly large scales of production, the efficiency of the overall operation goes up, thereby yielding more output for a given amount of effort. Yet it is the case in social systems, of which the economy is a part, that increases in size eventually lead to qualitative changes as well.

Social sciences in general, and particularly economics, tend to be oblivious to tipping points, beyond which adding another increment leads to some reorganization of the system itself. In any system, there typically are interactions, thresholds, indirect effects, and other non-linearities (Prigogine \& Stengers, 1984; Burns \& LeMoyne, 2003a).

The transformation of the potato crop to fewer varieties on larger tracts of land (in DeFries's terms, the "ratchet"), led to a truncation of the biodiversity, which had before served as a natural break to a fungus being able to wipe out entire crops. What had been confined to smaller, isolated places, was now in a position to become more widespread.

Yet the retrospective lessons of the Potato Famine go largely unheeded, even now. Especially in cases where businesses ratchet up into large-scale production without planning or preparing for the inevitable hatchet of collapse to follow.

In many business systems, there is a bias toward large scales of production, typically at the expense of smaller and more ecologically sustainable ones. This manifests in ways too many to enumerate (for further discussion, see Schumacher, 1975/1989). Some salient examples in terms of the natural environment include unsustainable agricultural practices such as monocropping, and large concentrated animal feeding operations (CAFOs) at the expense of small and ecologically integrated farming.

A more pragmatic approach from the standpoint of ameliorating the mismatches between the sciences of economics and human ecology would be to frame a series of research question in terms of what is done optimally, and at what scale? For whom and for what is it optimal? As Max Weber (1921/1978) pointed out in Economy and Society, in large-scale formally rational systems, efficiency of the system itself (many aspects of which may indeed be measurable in terms of money) tends to trump the needs of the people subject to it. To that, we would add that it also trumps environmental concerns through monetarizing nonmonetary values (e.g., fresh air, clean water) or by ignoring ("externalizing") them completely. In such a dynamic, money had become an end in itself (Simmel 1907/1978). 


\section{Hyperspecialization and comparative advantage}

When individual workers are highly specialized in just a small and focused part of a larger project, and those tasks are coordinated, the overall productivity will, in the short run, outstrip a simple aggregate of each individual making the overall product. Again, taken at face value and within circumscribed ranges, this gives the appearance of an obvious truth - a scientific truth from the standpoint of economics and a reified one from that of business.

By extension, people specializing at what they could do efficiently and leaving the other tasks to others who could do their respective tasks more efficiently would redound to efficiency for the overall system. David Ricardo (1817) moved the focus of Adam Smith's absolute advantage theory to what became more popularly accepted in mainstream economics - the principle of comparative advantage. It soon became known as the law of comparative advantage.

As England industrialized, its trading partners were encouraged, or coerced, into taking other roles. Ireland was gradually drawn into an unequal exchange relationship with England, in which English capital (and the political power with which it was intertwined) controlled Irish resources and labor.

Ricardo's law was repopularized in the 20th century by Paul Samuelson (1947/2011) who, when challenged to name a single principle of economics that was both non-trivial and true, argued that the law of comparative advantage fit both criteria. ${ }^{5}$ But is it true and, if so, under what conditions? More importantly, even if it is "true," is it true in such a way that it could or should trump other considerations, most notably human well-being and ecological sustainability?

Taken at face value, these interrelated economic principles-economies of scale, hyperspecialization, and the law of comparative advantage - sound quite reasonable. With The Wealth of Nations appearing in 1776 in the early stages of the Industrial Revolution, these became guiding principles that organized the workhouses of urban England, and the farming economy of Ireland.

The excesses of what this wrought in the early Industrial Revolution served as much of the fodder for novels by Charles Dickens and were critiqued by social theorists such as Marx and Engels (Stearns \& Burns, 2011). These sorts of practices, taken to an extreme, also led to the Irish Potato Famine of the 19 th century.

5 Samuelson (1947/2011) himself, for example, attempted to synthesize a number of important ideas from within (particularly the ideas in the tradition of J. M. Keynes) and without (most importantly, thermodynamics) economics with the dominant neo-classical model. Yet, if we were to engage this through a framework of human ecology, we would need to consider the trajectory of such ideas in the common consciousness. 
Yet these lessons were not internalized by global markets - far from it. By the early 20th century, these principles had gained enough momentum, particularly in the eyes of those with access to capital and the concomitant political power to bolster it, to base entire systems of production on them. The relationship of Ireland and England was to be replicated, in innumerable variations, around the globe.

\section{Invisible hands, unanticipated consequences}

If Adam Smith's idea that the "invisible hand" of the market will result in the common good for humankind and, by extension, for the environment, was ever was true (and we are not suggesting that it was), it most certainly needs extensive qualification. Without that, the invisible hand becomes a truism, an article of faith no more or less bona fide, for example, than the old belief in "phlogiston" in alchemy (for an example of a contemporary economist promulgating thought in this mode, see Simon, 1983/1984).

Bracketing questions about how much of the invisible hand is reified to begin with, questions about time and scale of the invisible hand need to be examined closely. How long, for example, does the invisible hand take to operate? When does it and when does it not operate? How tight or loose is the feedback loop? If it works in the smaller scale, does it also work in truly global dimensions that far outstrip even the scale of what the forward-thinking Smith could have imagined?

Even if it did work with total "efficiency," precisely as it should in the textbooks, so what? At best, it privileges the variable of market price over other aspects of life and the human condition, most notably health and the natural environment.

It may be, for example, that the price of potatoes does indeed go up with a general famine. But more important questions speak to the human and ecological costs and outcomes. To be sure, higher prices do not get the potatoes back. In fact, that could set off a perversity in the market to actually increase the overall ecological rift (Foster, York, \& Clark, 2011), because as arbitrageurs see rising prices, their incentives go up to engage in even more ecologically marginal activity in attempts to pursue potentially greater profits.

If the invisible hand works efficiently within certain ranges, it tends not to work nearly as well outside of those ranges. Schnaiberg and Gould (2000), for example, discuss the perverse effects of luxury goods markets, particularly when there are huge concentrations of capital in a few hands. What is "rational" for the rich may in fact be irrational for someone with more limited resources, and vice versa. What logic does the market then follow? With the crash in 
potatoes, the land becomes reduced to a fungible resource for the absentee landlords who then see it as "rational" to shift to an exportable cash crop of wheat or corn.

In human ecological terms, the invisible hand can be seen as a type of evolutionary process. While its effects are seen most readily on the macrostructural level, the assumption of enlightened self-interest operates primarily on the micro level. There is a long-standing debate among human ecologists, as well as sociologists about the efficacy of a more micro or macro approach (for discussion of the relative merits of micro and macro analysis in ecology, see Richerson, 1977).

From a metatheoretical perspective, it is important to consider the scope or range of a theory. A theory may work well within certain ranges, and poorly in others (Walker \& Cohen, 1985). When considering the invisible hand proposition, it is important to ask who is making a decision, and for whom is it "rational"? History shows that power dynamics play themselves out in such cases (e.g., Beckert, 2014; Mintz, 1985; Jacob, 2015).

\section{Time frames and feedback loops}

While the idea of the invisible hand guiding the market, particularly to encourage ingenuity when it is needed to solve problems of shortages, has been around since the time of Adam Smith, it has most recently been championed by influential economists (e.g., Simon, 1983/1984), and has become particularly so with neo-conservative think tanks and talk show hosts. It is so ubiquitous that it has become part of the common way of thinking.

Yet here, the common way of thinking leads us astray. Certainly if one resource is depleted, the invisible hand of the market will see to it that another resource is substituted. But even if that is true, it is myopic at best. When the potato crop failed, Irish tenants could not simply substitute wheat for potatoes because the yield in tons and calories from wheat were so much lower than they were for potatoes.

Ingenuity operates differently for people, depending upon their access to, and relationship with, natural resources. Many of the Irish adapted, as best they could, by leaving, or perhaps by stealing or by rebelling.

In a related vein, it bears asking: In what time frame does the invisible hand work? It may well be that shortages do indeed encourage ingenuity because, after all, as the folk wisdom dictates, "necessity is the mother of invention." But particularly in the increasing pace of modern times, when technology and population pressures are creating problems and shortages rapidly, can the 
responses of ingenuity keep up? Further, new inventions have their unintended and unforeseen consequences as well, which in turn will require a need for a focus of attention and resources.

Shortages, of course, are of central concern with the natural environment. In fact, economics tends to reduce shortages to an economic problem-one of supply. As Hardin (1991) points out, every shortage of supply can be seen as a "longage" of demand. The demand in the case of the Potato Famine was increased greatly by the exporting of food.

More profoundly, shortages may come to compromise the well-being of the planet and its ecosystems, threatening the health or even lives of those dependent upon it. Economic theory tends to ignore problems of temporality with the invisible hand. The longer it takes for the invisible hand to restore equilibrium, the more devastating the consequences. In terms of the adaptive cycle, the longer and more profound the ratchet phase, the harder the hatchet falls when the inevitable move to establish equilibrium occurs.

\section{Hard and soft limits to growth}

To be sure, there is a place to consider the law of supply and demand-but with what limit? Even if it is true that the market is subject to the laws of supply and demand, the ethical question arises as to whether it makes sense to let things go until the harsh reality of undersupply with inelastic demand brings misery to humanity.

Here it is worthwhile to consider the differences between soft, voluntary limits and hard limits. Using a resource until the bitter end represents a hard limit. The depletion of a scarce resource makes it, by definition, scarcer with use. This tends to price low-end users out of the market. In a truly free market, there typically are only hard limits.

A cross-cutting entity (e.g., government regulators) can do nothing and wait for the hard limit to kick in, or can help ameliorate the effect. The Irish Potato Famine case was so tragic because, in no small part, the people who were so devastated had no representation. Those in power were able to promulgate their own hegemonic version of the reality, as the story of Trevelyan's reign attests.

In virtually any case, and the Irish case is but one example - albeit an extreme one - resources are distributed unequally. That inequality gets more severe and more complex with greater shortage. The entire social system works differently under conditions of shortage than under plenitude. 
One way a society can handle shortages is to wait until the last minute and deal with undersupply and hyper-demand. Economists like Ester Boserup (1965) and Vern Ruttan (Binswanger \& Ruttan, 1978) would argue that these conditions "induce innovations," which they do, but the transitions from crop to crop are often more halting than the theoretical constructs would have us believe. Certainly, the "helping hand" of government assistance was not available to distressed Irish tenant farmers during the 1840s.

The time and trajectory of change are crucial social variables that tend to be ignored in the glib fatalism of belief in the invisible hand. A gradual change allows people to adapt, perhaps even gracefully. A quick change is typically catastrophic (for an extended discussion, see Stiglitz, 2003). In terms of the adaptive cycle, a crucial way to hedge against the seriousness of the "hatchet" is to go easy on the "ratchet" that comes before it by, for example, avoiding monocropping.

\section{Notes on sustainability and equity}

Every time a resource is used, it impacts others. Particularly with globalization, there is the increased ability for resource transfer between places. This process is characterized in the literature in terms of unequal ecological exchange, the ecological footprint, and metabolic rift (for reviews, see Jorgenson, 2003, 2004; Jorgenson \& Burns, 2007). As we have seen, the Irish Potato Famine, and events surrounding it, was rife with unequal exchange.

Processes of resource transfer are guided by norms. While those norms may not be explicitly stated, people ignore them at their peril. The norm of the "free" marketplace is no small part of the default, although a truly free market may be neither common nor desirable. Ideally, a normative system is most rich, nuanced and robust when tempered by humanistic concerns. Yet the norms and ideologies that often carry the day are promulgated by those who also have sufficient power to benefit from the unequal exchange.

\section{Perverse consequences of science and technology in an age of globalization}

These considerations, particularly those involving mismatches of scale, come into play again when the "pivot" is applied. Much of technology tends to be organized around routinized large scales of production and consumption, and so small systemic eccentricities, or imbalances, tend to be magnified. This combination of entropy in parts of the system, multiplied by large-scale production, leads to potentially catastrophic consequences. This then is the crux of why "technology" is such a potential problem in the contemporary era of global scales of production and consumption (for further discussion, 
see Burns \& Jorgenson, 2007). Moving into the Third Millennium, an important focus of human ecological research could be on the pivot of technology, with an eye to ensuring the solutions introduced do not in turn cause larger problems than they solve.

The organization of the global economy comes with a number of tradeoffs, which, if not balanced, lead to serious social and environmental problems. Particularly with the intertwining of technology with the economy, there is the increased risk of the upset of the natural balance of the world's ecosystems.

As Allen Schnaiberg (1980) has pointed out (for further discussion in a structural human ecological framework, see Dietz, 2013), there is a mismatch between the leading edge of technology that is intertwined with the treadmill of production of the modern economy, and the following technology that could potentially clean up and address environmental problems. In the words of Garrett Hardin $(1968,1998)$, technology creates problems it cannot solve.

The scientific method, as it facilitates technology and business interests, carries with it many of the economic perversities we have been considering, particularly the problem of externalities. The science of narrowly businessdriven technology tends to focus on circumscribed aspects of reality and in so doing largely ignores other factors.

In its focus on some circumscribed aspect of an overall system, science and the technology stemming from it is able to bring a greater level of control over what is under its microscope. Yet imposing order on some aspect of a system often imposes entropy on other parts of the system (Prigogine \& Stengers, 1984). This can be seen under a number of lenses, including that of post-normal risk. Typically, the most profoundly affected parts are those most closely connected ecologically with the part under study and manipulation, and yet defined out of the system for purposes of scientific investigation and technological development.

The problem with the culture of business and its relationship with technology, particularly in late modern times, is not so much a hostility to the natural environment (although there is plenty of that to go around), nearly so much as the tendency to treat the environment as an externality. There is a general tendency to view the natural environment as if it is limitless, when in fact it is not.

A number of theorists have noted how institutional practices, over time, become part of the culture (Burns, 1999; Burns \& LeMoyne, 2003b). At the dawn of the Third Millennium, a case can be made more strongly than ever that there is an emergent global culture of late modernity (Burns, 2009). This is characterized by practices and beliefs that reflect many of the ideas we have examined herein- 
economies of scale, mass externalization, discounting the future, and a growth model that is commonly characterized in human ecology as the treadmill of production.

With the enframing (Heidegger, 1967) of destructive technologies that make sense from a business standpoint, but not from that of the adaptive cycle, we can see a collision course of the global economy with its value of continual growth, and the necessary limits of the natural ecology. The separate paths of the world economy and the adaptive cycle cannot diverge much longer. To the extent they do, the risks are truly daunting.

\section{Conclusion}

The structure of the world economy is based on a number of ideas that are limited. Particularly problematic are the mismatches between the ways in which the world economy operates, and the constraints of the adaptive cycle experienced in natural systems.

Bringing these two worlds into alignment will be no easy task, and yet the consequences of not doing that will, over time, prove to be catastrophic. As a guiding metatheoretical principle, it is important to understand and to address the mismatches between these two systems.

As an extended example, we looked at the Potato Famine of the 1840s in Ireland. We then looked at how many of the ways of thinking and acting institutionally are at least as embedded now as they were then.

In sum, in this article, we have looked more closely at the structure of some of these mismatches and their related perversities, including questions of scale, externalization, comparative advantage, the invisible hand, and discounting the future. Each in their own right serve as rich theoretical guideposts. In combination, they serve as an overarching way of making sense of, and addressing in a praxeological way, the daunting ecological problems of the Third Millennium.

\section{References}

Barnett, V. (1998). Kondratiev and the Dynamics of Economic Development. London: Macmillan.

Becker, G. (1976). Altruism, egoism and genetic fitness: Economics and sociobiology. Journal of Economic Literature, 14, 817-826. 
Beckert, S. (2014). The Empire of Cotton: A Global History. New York: Alfred A. Knopf.

Binswanger, H. P., \& Ruttan, V. W. (1978). Induced Innovation: Technology, Institutions and Development. Baltimore, MD: The Johns Hopkins University Press.

Boserup, E. (1965). The Conditions of Agricultural Growth. Chicago, IL: Aldine Publishing Company.

Burns, T. J. (1999). Rhetoric as a framework for analyzing cultural constraint and change. Current Perspectives in Social Theory, 19, 165-185.

Burns, T. J. (2009). Culture and the natural environment. In P. Lopes and A. Begossi (Eds.), Current Trends in Human Ecology (pp. 56-72). Newcastle upon Tyne, UK: Cambridge Scholars Press.

Burns, T. J., \& Jorgenson, A. K. (2007). Technology and the environment. In C. D. Bryant and D. L. Peck (Eds.), 21st Century Sociology: A Reference Handbook (pp. 306-312). Thousand Oaks, CA: Sage.

Burns, T. J., Kick, E. L., \& Davis, B. L. (2006). A quantitative, cross-national study of deforestation in the late 20th century: A case of recursive exploitation. In A. K. Jorgenson and E. L. Kick (Eds.), Globalization and the Environment (pp. 37-60). Leiden, The Netherlands: Brill.

Burns, T. J., \& LeMoyne, T. (2003a). Chaos and complexity theories: Tools for understanding social processes. International Journal of the Humanities, $1,941-950$.

Burns, T. J., \& LeMoyne, T. (2003b). Epistemology, culture, and rhetoric: Some social implications of human cognition. Current Perspectives in Social Theory, 22, 71-97.

Chase-Dunn, C., \& Hall, T. (1997). Rise and Demise: Comparing World Systems. Boulder, CO: Westview Press.

DeFries, R. (2014). The Big Ratchet: How Humanity Thrives in the Face of Natural Crisis. New York, NY: Basic Books.

Dietz, T. (2013). Epistemology, ontology, and the practice of structural human ecology. In T. Dietz and A. Jorgenson (Eds.), Structural Human Ecology: New Essays in Risk, Energy, and Sustainability (pp. 31-52). Pullman, WA: Washington State University Press.

Dietz, T., \& Burns, T. R. (1992). Human agency and the evolutionary dynamics of culture. Acta Sociologica, 35, 187-200. 
Dietz, T., \& Jorgenson, A. (Eds.). (2013). Structural Human Ecology: New Essays in Risk, Energy, and Sustainability. Pullman, WA: Washington State University Press.

Fain, H. D., Burns, T. J., \& Sartor, M. (1994). Group and individual selection in the human social environment: From behavioral ecology to social institutions. Human Ecology Review, 1(2), 335-350.

Foster, J. B., York, R., \& Clark, B. (2011). Ecological Rift: Capitalism's War on the Earth. New York: Monthly Review Press.

Gunderson, L., \& Hollings, C. S. (Eds.). (2002). Panarchy: Understanding Transformations in Human and Natural Systems. Washington, DC: Island Press.

Hardin, G. (1968). The tragedy of the commons. Science, 162(3859), 1243-1248.

Hardin, G. (1991). From shortage to longage: Forty years in the population vineyards. Population and Environment: A Journal of Interdisciplinary Studies, 12(3):339-349.

Hardin, G. (1998). Extensions of "The Tragedy of the Commons." Science, $280(5364), 682-682$.

Heidegger, M. (1967). What Is a Thing? Chicago, IL: Henry Regnery.

Hollings, C. S., (1973). Resilience and stability in ecological systems. Annual Review of Ecology and Systematics, 4, 1-23.

Jacob, H. E. (2015). Coffee: The Epic of a Commodity, reissue edition. New York: Skyhorse Publishing.

Jorgenson, A. K. (2003). Consumption and environmental degradation: A crossnational analysis of the ecological footprint. Social Problems, 50, 374-394.

Jorgenson, A. K. (2004). Uneven processes and environmental degradation in the world economy. Human Ecology Review, 11, 103-113.

Jorgenson, A. K. (2006). Unequal ecological exchange and environmental degradation: A theoretical proposition and cross-national study of deforestation, 1990-2000. Rural Sociology, 71(4), 685-712.

Jorgenson, A. K. (2013). Population, affluence, and greenhouse gas emissions: The continuing significance of structural human ecology and the utility of STIRPAT. In T. Dietz and A. Jorgenson (Eds.), Structural Human Ecology: New Essays in Risk, Energy, and Sustainability (pp. 139-157). Pullman, WA: Washington State University Press. 
Jorgenson, A. K., \& Burns, T. J. (2007). The political-economic causes of change in the ecological footprints of nations, 1991-2001: A quantitative investigation. Social Science Research, 36, 834-853.

Liu, J., Hull, V., Batistella, M., DeFries, R., Dietz, T., Fu, F., Hertel, T. W., Izaurralde, R. C., Lambin, E. F., Li, S., Martinelli, L. A., McConnell, W., Moran, E. F., Naylor, R., Ouyang, Z., Polenske, K. R., Reenberg, A., de Miranda Rocha, G., Simmons, C. A., Verburg, P. H., Vitousek, P., Zhang, F., Zhu, C. (2013). Framing sustainability in a telecoupled world. Ecology and Society, 18, 26.

Lux, K. (1990). Adam Smith's Mistake. Boston, MA: Shambhala.

McCloskey, D. N. (1998). The Rhetoric of Economics. Madison, WI: University of Wisconsin Press.

McLaughlin, P. (2012). The second Darwinian revolution: Steps toward a new evolutionary environmental sociology. Nature and Culture, 7(3), 231-258.

McLaughlin, P., \& Dietz, T. (2008). Structure, agency and environment: Toward an integrated perspective on vulnerability. Global Environmental Change, $18,99-111$.

Meyfroidt, P., Rudel, T., \& Lambin, E. (2010). Forest transitions, trade, and the displacement of land use. Proceedings of the National Academy of Science (PNAS), 107(49), 20917-20922.

Mintz, S. W. (1985). Sweetness and Power: The Place of Sugar in Modern History. New York: Viking-Penguin.

Mokyr, J., \& O'Grada, C. (2002). What do people die of during famines?: The Great Irish famine in comparative perspective. European Review of Economic History, 6, 339-363.

O'Connor, J. (1998). Natural Causes: Essays in Ecological Marxism. New York: Guilford.

O'Grada, C. (1999). Black '47 and Beyond: The Great Irish Famine in History, Economy, and Memory. Princeton, NJ: Princeton University Press.

Prigogine, I., \& Stengers, I. (1984). Order Out of Chaos. New York, NY: Bantam.

Ricardo, D. (1817). On the Principles of Political Economy and Taxation. London, UK: John Murray.

Richerson, P. J. (1977). Ecology and human ecology: A comparison of theories in the biological and social sciences. American Ethnologist, 4, 1-26. 
Richerson, P. J., \& Boyd, R. (1998). Homage to Malthus, Ricardo, and Boserup: Toward a general theory of population, economic growth, environmental deterioration, wealth, and poverty. Human Ecology Review, 4(2), 85-90.

Ritzer, G. (1975). Sociology: Multi-Paradigm Science. Boston, MA: Allyn and Bacon.

Ritzer, G. (1991). Metatheorizing in Sociology. Lexington, MA: Lexington Books.

Ritzer, G. (Ed.). (1992). Metatheorizing. Newbury Park, CA: Sage.

Samuelson, P. (1947/2011). Foundations of Economic Analysis. Cambridge, MA: Harvard University Press.

Schnaiberg, A., \& Gould, K. A. (2000). Environment and Society: The Enduring Conflict. Caldwell, NJ: Blackburn Press.

Schnaiberg, A. (1980). The Environment: From Surplus to Scarcity. New York: Oxford University Press.

Schneider L. C., \& Fernando, N. 2010. An untidy cover: Invasion of Bracken Fern in the shifting cultivation systems of Southern Yucatán, Mexico. Biotropica, $42(1), 41-48$.

Schumacher, E. F. (1973/2010). Small Is Beautiful: Economics as if People Mattered. New York: Harper.

Schumacher, E. F. (1975/1989). Small Is Beautiful. New York, NY: Harper Perennial.

Sen, Amartya. 1983. Poor, Relatively Speaking. Oxford Economic Papers, 35(2), 153-168.

Simmel, G. (1907/1978). The Philosophy of Money. Ed. and Trans. by T. Bottomore and D. Frisby. London: Routledge and Kegan Paul.

Simon, J. (1983/1984). The theory of price-changing and monopoly power. Journal of Post-Keynesian Economics, 6(2), 198-213.

Smith, A. (1776). An Inquiry into the Nature and Causes of the Wealth of Nations. London: W. Strahan.

Spence, M. (2000). Capital against nature: James O'Connor's theory of the Second Contradiction of Capitalism. Capital \& Class, 24, 81-109.

Stearns, A. E., \& Burns, T. J. (2011) About the human condition in the works of Dickens and Marx. CLCWeb: Comparative Literature and Culture 13.4. Accessed at dx.doi.org/10.7771/1481-4374.1689. 
Stiglitz, J. E. (2003). Globalization and Its Discontents. New York, NY: W. W. Norton \& Company.

Vayda, A. P. (1988). Actions and consequences as objects of explanation in human ecology. In R. J. Borden, J. Jacobs, and G. L. Young (Eds.), Human Ecology: Research and Applications (pp. 9-18). College Park, MD: Society for Human Ecology.

Walker, B., \& Salt, E. (2006). Resilience Thinking: Sustaining Ecosystems and People in a Changing World. Washington, DC: Island Press.

Walker, H. A., \& Cohen, B. P. (1985). Scope statements: Imperatives for evaluating theory. American Sociological Review, 50(3), 288-301.

Wallerstein, I. (2004). World System Analysis: An Introduction. Durham, NC: Duke University Press.

Weaver, R. M. (1984). Ideas Have Consequences. Chicago, IL: University of Chicago Press.

Weber, M. (1921/1978). Economy and Society. Berkeley, CA: University of California Press.

York, R. (2013). Metatheoretical foundations of post-normal prediction. In T. Dietz and A. Jorgenson (Eds.), Structural Human Ecology: New Essays in Risk, Energy, and Sustainability (pp. 19-29). Pullman, WA: Washington State University Press. 
This text is taken from Human Ecology Review, Volume 22, Number 1, 2015, published 2015 by ANU Press, The Australian National University, Canberra, Australia. 